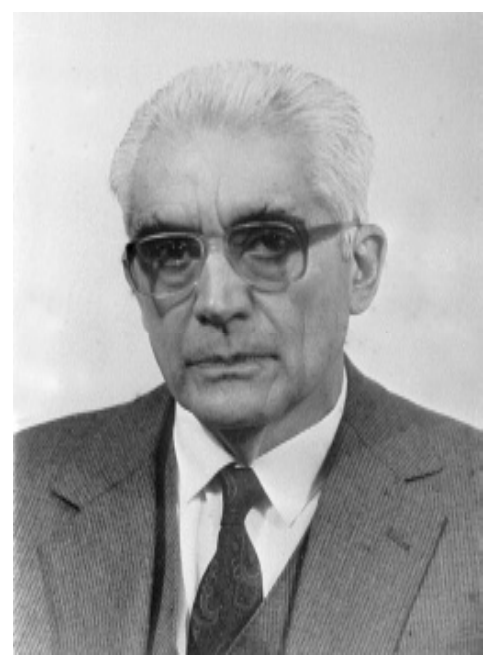

\title{
In memoriam: Prof. Dr. José Roberto de Albuquerque Fortes (1924-2002)
}

Por ser um decano e ter participado do início do Instituto de Psiquiatria da Faculdade de Medicina da Universidade de São Paulo, tenho sido convidado para escrever algumas linhas in memoriam daqueles que se foram. Se de um lado muito me honra esta escolha, por outro lado sou levado a ter que administrar meus sentimentos de profundo pesar e perda, ao rememorar a vida de colegas com os quais partilhei grande parte de minha vida. Tenho feito um luto após outro. Perdemos o Prof. Antonio Carlos Pacheco e Silva, o Prof. Fernando de Oliveira Bastos, o Prof. João Carvalhal Ribas, o Prof. Walter Nelson Cardo e vários outros colegas do início dessa grande jornada do Instituto de Psiquiatria. A Psiquiatria brasileira, especialmente a paulista, perdeu mais um de seus colaboradores.

Companheirismo e solidariedade diante de uma causa comum criam laços afetivos fortes. Tudo começou com a fundação do atual Instituto de Psiquiatria, por meio de seu primeiro líder, o Prof. Antonio Carlos Pacheco e Silva (1898-1988). Naquele tempo, denominado "tempo dos catedráticos", todos nós, assistentes do Prof. Pacheco e Silva, éramos chamados "os assistentes do Pacheco".

Tivemos a oportunidade de conviver muitos anos com o Prof. José Roberto de Albuquerque Fortes.

O Prof. Fortes era natural de São Paulo e foi casado com Maria Ercília Quintela Fortes.

O Prof. Fortes foi aprovado no vestibular da FMUSP em 1945, em 7o lugar. Nessa época vários países com tendências, ou mesmo regimes, ditatoriais estavam se transformando em um clima mais liberal e democrático. Essa revolução social, no sentido democrático, impregnou o estudante de medicina José Roberto de Albuquerque Fortes e este foi um dos seus atributos mais importantes quando na Regência de Titular da Disciplina de Psiquiatria da FMUSP. Quando estudante de medicina, desempenhou várias atividades no plano associativo, ocupando cargos eletivos no Centro Acadêmico Oswaldo Cruz. Foi eleito Presidente do Centro Acadêmico Oswaldo Cruz, tendo sido orador eleito por duas vezes.

O Prof. Fortes concluiu o curso médico em 1950. Iniciou sua atividade profissional trabalhando em Clínica Médica. Em 1952 iniciou seu estágio, como médico voluntário, no Ambulatório de Psiquiatria do Instituto de Psiquiatria sob a regência do Prof. A. C. Pacheco e Silva. Em dezembro desse mesmo ano, foi indicado para médico auxiliar. Recebia ensinamentos dos mais experientes, como o Prof. Pacheco e Silva, o Prof. Fernando Bastos e o Prof. Carvalhal Ribas, entre outros.

Como sabemos, em 1952 começou a funcionar o Ambulatório com o prédio do Instituto de Psiquiatria parcialmente terminado. A primeira internação ocorreu em outubro de 1953. Até a década de 40 a insulinoterapia e a convulsoterapia eram os tratamentos predominantes em Psiquiatria. A partir da década de 50 houve uma transformação graças às descobertas em Psicofarmacologia. O Prof. José Roberto de Albuquerque Fortes, junto com o Prof. Pacheco e Silva e Henrique Marques de Carvalho, participou dos primeiros trabalhos sobre o emprego da clorpromazina em doses maciças para o tratamento de várias síndromes mentais, principalmente a esquizofrenia.

Defendeu o seu doutoramento em 1959 (o etilismo crônico e crises convulsivas) e sua livredocência em 1964 (Psilocibina e Alcoolismo Crônico). Com intensa atividade no ensino e na pesquisa, desde 1952 até a sua aposentadoria compulsória em 1994, contribuiu nas áreas de Psiquiatria Clínica, Psicologia Médica e na área de Psicossomática. Além de intensa atividade no ensino da disciplina de Psiquiatria da FMUSP, lecionou também em outras instituições. Em 1958, 1959 e 1960 ministrou aulas na Escola Paulista de Medicina, na disciplina de Psiquiatria, sob a regência do Prof. Carvalhal Ribas. Aqui, os nossos caminhos também se cruzaram, pois em 1961, a convite do Prof. Carvalhal Ribas, fui demonstrar, na Escola Paulista de Medicina, em aulas práticas sobre o alcoolismo, os novos rumos do tratamento do delirium tremens. O Prof. Fortes, desde o início de sua carreira, interessou-se pelo 
estudo do alcoolismo e suas manifestações clínicas. Foi nessa ocasião que tivemos discussões acadêmicas calorosas e muito proveitosas. O Prof. Fortes, estudioso do alcoolismo, publicou um livro sobre este tema em 1975 e um outro, atualizado, em 1991. Sua atividade de ensino não se limitou aos cursos de graduação e pós-graduação, mas também ministrou aulas em cursos de extensão universitária e em campanhas de difusão cultural. Participou de diretorias de diferentes entidades científicas, desde o cargo de secretário ao de presidente.

Foi presidente do Departamento de Psiquiatria da Associação Paulista de Medicina, presidente da Associação Psiquiátrica de São Paulo, etc.

Trabalhava não só no Instituto de Psiquiatria, mas também no Hospital do Servidor Público Municipal, onde organizou e estimulou o ensino de Psiquiatria. Em 1981 foi indicado e empossado no cargo de Professor Adjunto do Departamento de Psiquiatria da FMUSP. Foi substituto do Titular, nas suas ausências, em diversas ocasiões, como em 1978, 1979, 1980, 1981 e 1982.

O número de trabalhos publicados é muito grande, juntamente com o grande acervo de contribuições científicas encontradas no seu memorial.

O Prof. Fortes participou como membro de bancas examinadoras para defesas de mestrado, doutorado e livre-docência, para concursos de ingresso no Departamento de Psiquiatria, etc.

Muitos psiquiatras, hoje nossos conhecidos, já passaram pelo seu crivo. Citaremos apenas alguns nomes: Prof. Dr. Maurício Levy, Prof. Dr. Jorge W. F. Amaro, Prof. Dr. Oscar Rezende de Lima, Profa. Dra. Eneida B. Matarazzo, Prof. Dr. Zacaria Borge Ali Ramadan e muitos outros.

O Prof. Fortes foi membro de várias associações científicas; entre elas lembramos que era Membro Emérito da Academia de Medicina de São Paulo.

Ele galgou os degraus da vida universitária sem queimar etapas, chegando ao ápice com naturalidade e maturidade.

Em 1984, na posse solene ao cargo de Prof. Titular do então Departamento de Neuropsiquiatria da FMUSP, assim escreveu o Prof. Carvalhal Ribas: "Em sessão solene, realizada no salão nobre da FMUSP e presidida pelo Diretor Prof. Dr. Silvano Raia, efetuou-se a solenidade da posse do Prof. Dr. José Roberto de Albuquerque Fortes ao cargo de Professor Titular do Departamento de Neuropsiquiatria da FMUSP. A mesa foi presidida pelos Professores Pacheco e Silva, Fernando Bastos, Carvalhal Ribas e Xavier Guimarães. O Prof. Fortes foi introduzido no recinto da congregação pelos Professores Carlos da Silva Lacaz, Spina França Neto e Armando Canger Rodriguez. Segundo ritual de praxe, o auditório de pé, o Prof. Dr. Silvano Raia, assessorado pelo Dante Nese, investiu o novo Professor no cargo a que fizera jus".

Nas várias décadas que trabalhávamos juntos, pudemos constatar algumas linhas mestras de sua personalidade: era uma pessoa do tipo introvertido, porém muito prudente, com grande noção de realidade e bom senso e com muita constância no trabalho. O que se destacou de sua personalidade durante a regência foi o seu espírito democrático. O Prof. Fortes, ao assumir, em 1984, a disciplina de Psiquiatria e a presidência do Conselho Diretor do Instituto de Psiquiatria, encontrou a instituição em fase de transformação, onde os médicos, pós-graduandos e residentes procuravam constituir equipes formando grupos especializados em uma determinada área, com finalidades assistenciais, didáticas e de pesquisa. Foi graças ao espírito democrático daquele novo Titular que se permitiu a instalação e o desenvolvimento desses grupos. Assim surgia o Grupo Interdisciplinar de Estudos do Alcoolismo e Fármaco-dependências (GREA), o Grupo de Doenças Afetivas (GRUDA), o Ambulatório de Ansiedade (AMBAN), o Projeto Esquizofrenia (PROJESC), o Ambulatório de Bulimia e Transtornos Alimentares (AMBULIM), etc.

O Conselho Diretor, em 1987, na gestão do Prof. Fortes, aprovou a construção de mais duas alas no 4ํaa andar, com a intenção de instalar nova enfermaria e um centro de convivência. A Prof. Dra. Eneida Baptistete Matarazzo foi quem assumiu a liderança para a construção dessas alas.

O Prof. Fortes permitiu e estimulou que vários psiquiatras, vinculados ao Instituto de Psiquiatria, realizassem estágios de aperfeiçoamento no "Maudsley Hospital" da Universidade de Londres.

Com este pequeno resumo da vida profissional desse ilustre colega desejamos deixar, por escrito, em meu nome e em nome dos colegas do Departamento de Psiquiatria, nossa homenagem póstuma.

Prof. Dr. Jorge W. F. Amaro

Professor Associado Permissionário do Departamento de Psiquiatria da Faculdade de Medicina da Universidade de São Paulo 